\title{
Assessing the Exchange Rate Volatility as an External Shock to Chinese Economy
}

\author{
Mohammad Naim Azimi ${ }^{1}$ \\ ${ }^{1}$ Department of Industrial Economic and Business Administration, Rana University, Kabul, Afghanistan \\ Correspondence: Mohammad Naim Azimi, Department of Industrial Economics and Business Administration, \\ Rana University, Kabul 5252, Afghanistan. Tel: 937-9-006-0073. E-mail: vc@ru.edu.af or \\ naim.researchpapers.com.af
}

Received: December 17, 2015

Accepted: January 30, $2016 \quad$ Online Published: April 25, 2016

doi:10.5539/ijef.v8n5p277

URL: http://dx.doi.org/10.5539/ijef.v8n5p277

\begin{abstract}
Theoretically, the rate of exchange is one of the major drivers of inflation that influences the wholesale price index (WPI) in countries where significant emphasis is put over import and export like China. In this paper, the exchange rate's clustering volatility and its impulsiveness as an external shock to WPI is investigated on a set of time series data which represents 4,067 daily observation of Chinese Economy from August 12, 2004-September 30,2015 . The ordinary least square and weighted regression analysis reveal significant p-values of 0.000 for exchange rate that explain the WPI throughout the stated period. The autoregressive conditional heteroskedasticity and generalized autoregressive conditional heteroskedasticity model exhibit significant probability value of 0.000 and 0.044 respectively for WPI and the exchange rate. It is found that the previous days' volatility of WPI influences the future volatility of WPI as an internal shock in addition to the previous days' impulsiveness of the exchange rate which influences the future volatility of the WPI as an external shock. The testing models are thoroughly applied and their stability and validity are evidenced thereto.
\end{abstract}

Keywords: external shock, ARCH model, GARCH model, exchange rate, WPI, heteroskedasticity

\section{Introduction}

Exchange rate or the conversion value of one currency in relation to another is one of the macroeconomic variables that has been studied by many researchers worldwide and the existing literature provides vast number of contributions in empirical and theoretical investigations of the relationship between the exchange rate volatility and other macroeconomic variables i.e. international trade, foreign trade, export, import, purchase power parity and consumer price index (see for example, Grauwe, 1988; Arize et al., 2000; Aristotelous, 2001; $\mathrm{Xu}$, 2003; Aghion et al., 2009) though, comparatively its relationship with WPI as one of the important macroeconomic variables has not been that much considered. Baldwin and Krugman (1989) show a theoretical base for their argument that large exchange rate shocks such as the 1980s dollar cycle may have persistent effects on trading flows and the equilibrium exchange rate itself. Devereux and Engle (2002) state that the high volatility of real and nominal exchange rates may be due to the fact that local currency pricing eliminates the pass-through from changes in exchange rate to consumer price, while Dominguez and Tesar (2006) document the effect of exchange rate volatility on firm values (see also, Sahminan, 2007; Almeida et al., 1998). The sensitivity of exchange rate regime of a country is of highly considerable fact to control the fluctuating consuming price of a basket of goods sold both in terms of domestic and export trading. Cao et al. (2012) show the sensitivity of a currency that appears to play an important role in determining mark-up adjustment and the degree of pricing both to local and international markets (see also, Wang \& Barrett, 2007; Tokarick, 2008; Rahman \& Serletis, 2009). On the hand, Engle (2006) documents the optimization of pricing model in consideration with the importer's currency's fluctuating exchange rate while local prices are assumed to be stable. Specifically, an appreciation of Chinese currency against the foreign operating currencies would seem to require a dramatic change where chronic overvaluation in China's central planning period, but economic reforms have brought the real exchange rate closer to equilibrium and this reform in effect of exchange rate led to a substantial real depreciation of the Chinese currency after 1981 (Zhang, 2001) though, this claim was further criticized by Coudert and Couharde (2007) and Jiang and Kim (2013) who provide an insights about the possible undervaluation of the Chinese currency in comparison with the other emerging economies. 
In this paper, the real exchange rate effect of China is empirically investigated as an external shock to China's wholesale price index (WPI). Being specific, this paper investigates the effect of exchange rate volatility on WPI in Chines economy for the period August 12, 2004 to September 30, 2015 on a set of time series data arranged by daily basis in a generalized context of conditional heteroskedasticity which is the significance of this paper. The decomposition of time series data on daily basis helps to unveil the base of exchange rate fluctuating effects on the wholesale price index and facilitates the assessment of its future volatility as a function of previous days influence on the stated variable. The remainder of the paper is organized as follow: section 2 discusses the data and the research method, section 3 presents the data analysis and the results and section 4 presents discussion and concludes the paper.

\section{Data and Method}

This section deals with data and the research method applied in this paper to find out the result in a sequential order on the basis of which a rationally and evidentially supported conclusion is reached. The first part discusses the data and represents the descriptive statistics of the data collected and the second part presents the alternative estimation and econometric testing procedures used in this paper.

\subsection{Data Collection}

The set of data used in this paper represents the Chinese macroeconomic variables covering the period August 12, 2004 to September 30, 2015 with a total of 4,067 observations arranged on daily basis. The stated time series data has been retrieved from official website of Trading Economy and National Bureau of Economics Research (NBER) using the Quandl spreadsheet method.

Table 1. Descriptive statistics

\begin{tabular}{|c|c|c|c|c|c|}
\hline Variables & Observation & Mean & Std. Dev. & Min. & Max. \\
\hline Ex-Rate & 4,067 & 4.80953 & .7010054 & 3.2463 & 6.1613 \\
\hline WPI & 4,067 & 43.79026 & 21.12189 & 18.62 & 144.3 \\
\hline
\end{tabular}

Table 1 shows the descriptive statistics of two variables (Exchange Rate (Ex-Rate) and Wholesale Piece Index (WPI)) that are investigated in this paper. The total number of observation is 4,067 for each of the variables that are arranged on daily basis throughout the aforementioned period.
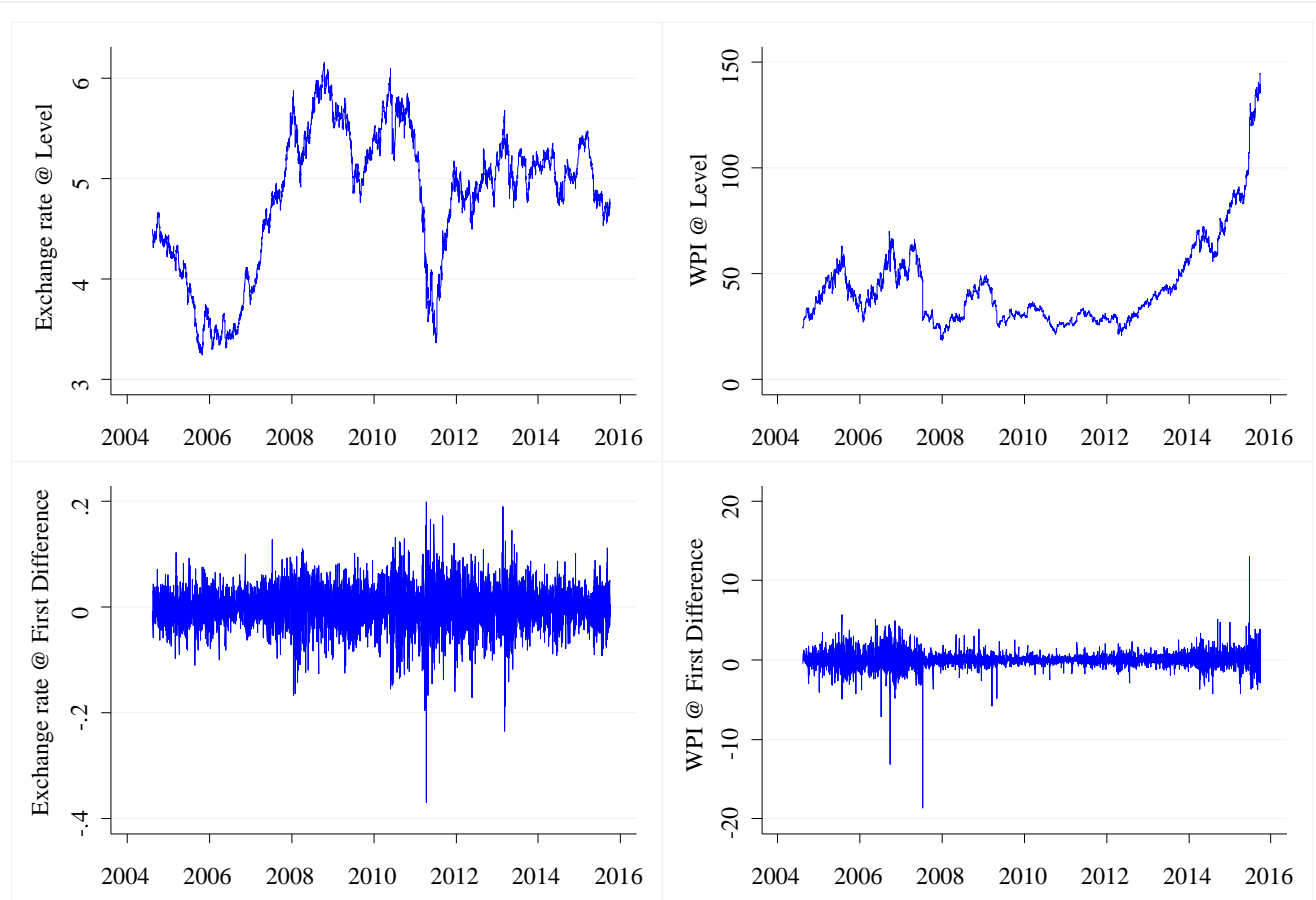

Figure 1. Variables line-plot at level and at first difference 
Before plotting the variables (Exchange rate and WPI) at level and at first difference, Augmented Dickey Fuller test developed by Dickey and Fuller (1979) was also applied to test the non-stationarity of the variables at level and their stationarity at first difference. Figure 1 reflects the same image as ADF test result, means that both variables are non-stationary at level and follow unit root while they are stationary at first difference and do not follow unit root. Therefore, we continue our computation on the variables at first difference of the stated variables.

\subsection{Estimation Alternative}

Testing the competing null hypothesis (the exchange rate affects the WPI as an external shock in Chinese economy) requires appropriate testing procedures for the purpose of which and in order to achieve an accurate result on which to base an appropriate conclusion, the following econometric models are applied that their brief discussion is sequentially discussed below:

\subsubsection{Linear Regression}

Initially, the dependent variable WPI and the explanatory variable Ex-Rate are regressed with an extra transformational term [aweight=Date] refers to as "Weighted Regression" which produces the coefficient and covariance matrix. The initial equation of the weighted regression model we fit is:

$$
y_{j} \sqrt{n_{j}}=\beta_{0} \sqrt{n_{j}}+\beta_{1} \chi_{1 j} \sqrt{n_{j}}+\beta_{2} \chi_{2 j} \sqrt{n_{j}}+u_{j} \sqrt{n_{j}}
$$

The estimate of the variance of residuals will be different and the transformed regression produces $S_{t}^{2}$ which is the estimate of our variables $=u_{j} \sqrt{n_{j}}$ where $n$ represents the number of observation in our data and is computed as:

$$
S_{a}^{t}=\frac{N}{\sum_{k} n_{k}} S_{t}^{2}=\frac{S_{t}^{2}}{\bar{n}}
$$

An OLS (Ordinary Least Square) regression is also to be computed to facilitate a comparative analysis between the results obtained from weighted regression with those of the OLS.

\subsubsection{Diagnostic Test for Heteroskedasticity}

Our data exhibits a large observation throughout the stated period in which some of the covariates may not be strictly exogenous. Particularly, the lags of the dependent variable for which, Durbin (1970) $d$ statistic test will be computed to check the null hypothesis that there is no $p$ th order autocorrelation. The Durbin Watson equation fit in our regression model $(1,2)$ is expressed as:

$$
d=\frac{\sum_{t=1}^{n-1}\left(\hat{u}_{t+1}-\hat{u}_{t}\right)^{2}}{\sum_{t=1}^{n} \hat{u}_{t}^{2}}
$$

$\hat{u}_{t}$ presents the residuals of the $t$ th observation in the above equation. To further the computation, a Lagrange Multiplier test developed by Engle (1982) is applied to investigate the Auto-Regressive Conditional Heteroskedasticity or simply ARCH effect in the residual. The model suggested by Engle which fits with our data is expressed as:

$$
u_{t}^{2}=\gamma_{0}+\gamma_{1} u_{t-1}^{2}+\ldots+\gamma_{p} u_{t-p}^{2}+\varepsilon
$$

The test statistics used is the $n R^{2}$ which is asymptotically distributed $\chi^{2}(p)$. The rejection of null hypothesis being no ARCH effect will lead us to accept the alternative and to continue the computation by using the ARCH and GARCH model $(1,1)$ and $(p, q)$.

\subsubsection{ARCH / GARCH}

The logic to select the ARCH (Auto-Regressive Conditional Heteroskedasticity) and GARCH (Generalized Auto-Regressive Conditional Heteroskedasticity $(1,1)$ model is to investigate the existence of clustering 
volatility in the series documented by the rejection of null hypothesis that there is no ARCH effect in the series. The ARCH and GARCH model allows us to test for future volatility as the function of prior volatility (series of low volatility tends to follow low volatility and series of high volatility follows high volatility) in our variables. The basic ARCH model is expressed as:

$$
\begin{gathered}
y_{t}=X_{t}+\beta+\varepsilon_{t} \\
\operatorname{D.WPI}\left(\varepsilon_{t}\right)=\sigma_{t}^{2}=\gamma_{0}+A(\sigma, \varepsilon)+B(\sigma, \varepsilon)^{2}
\end{gathered}
$$

The series of data used herein is a large amount of daily observation of $>4,000 \mathrm{t}$ suggests fitting the following conditional model to compute the $\operatorname{ARCH}$ and $\operatorname{GARCH}(p, q)$ model:

$$
y_{t}=X_{t} \beta+\sum_{i=1}^{p} \psi_{i} g\left(\sigma_{t-1}^{2}\right)+\sum_{j=1}^{p} \rho_{j}\left\{y_{t-j}-y_{t-j} \beta-\sum_{j=1}^{p} \psi_{i} g\left(\sigma_{t-j-i}^{2}\right\}+\sum_{k=1}^{q} \theta_{k} \varepsilon_{t-k}+\varepsilon_{t}\right.
$$

where $\beta$ represents the parameters of the regression model, $\psi$ is the parameter for ARCH-in-mean, $\rho$ exhibits the autoregression parameter and $\theta$ represents the moving average of the parameters. The model follows the Gaussian (normal) approach under which, after the computation of the ARCH and GARCH $(1,1)$ and $(p, q)$, post estimation residual will be created for further diagnostic tests of the model.

\subsubsection{Normal Distribution Test}

Portmanteau white noise test developed by Box \& Pierce (1970) is computed to test for normal distribution of the residual within the sample. The test relies on the fact that if $\chi(1), \ldots, \chi(\mathrm{n})$ is the realization from white noise process (Baum, 2005). The model we fit is written as:

$$
Q=n(n+2) \sum_{j=1}^{m} \frac{1}{n-j} \hat{\rho}^{2}(j) \rightarrow \chi_{m}^{2}
$$

$m$ presents the number of serial correlation calculated and $\rightarrow$ shows the convergence in distribution to a $\chi^{2}$ distribution with $\mathrm{m}$ degree of freedom and $\hat{\rho} j$ is the estimated autocorrelation for lag $\mathrm{j}$ (Baum, 2005). In connection to this, a Bartlett's white noise test is also performed to test whether residuals are within the bands. The equation of Bartlett's test (Bartlett, 1955) can be written as:

$$
\lim _{q} \rightarrow \infty \operatorname{Pr}\left(\max 1 \leq k \leq q \sqrt{q}\left|U_{k}-\frac{k}{q}\right| \leq a\right)=\sum_{j=\infty}^{\infty}(-1)^{j} e^{-2 a^{2} j^{2}}=G(a)
$$

$U_{k}$ presents the ordered uniform quintile. Thus the Bartlett's statistics equation can be written as:

$$
B=\max _{1} \leq k \leq q \sqrt{\frac{n}{2}}\left|\hat{F}_{k}-\frac{k}{q}\right|
$$

\begin{tabular}{|c|c|c|c|c|c|c|c|c|}
\hline \multirow[b]{2}{*}{ Source } & \multicolumn{3}{|c|}{ OLS Regression } & & \multicolumn{3}{|c|}{ Weighted Regression } & \\
\hline & SS & $\mathrm{df}$ & MS & & SS & $\mathrm{df}$ & MS & \\
\hline Model & 11210.1519 & 1 & 11210.1519 & & 7.81811605 & 1 & 7.81811605 & \\
\hline Residual & 1802771.73 & 4,065 & 443.486281 & & 657.857541 & 4,065 & .161834573 & \\
\hline Total & 1813981.89 & 4,066 & 446.134256 & & 665.675657 & 4,066 & .163717574 & \\
\hline WPI & Coef. & Std. Err. & $\mathrm{t}$ & $\mathrm{P}>|\mathrm{t}|$ & Coef. & Std. Err. & $\mathrm{t}$ & $\mathrm{P}>|\mathrm{t}|$ \\
\hline Ex-Rate & -2.368649 & .4711238 & -5.03 & $0.000 * * *$ & -.2892159 & .0416109 & -6.95 & $0.000 * * *$ \\
\hline
\end{tabular}

\section{Results}

In this section, the statistical analysis of the data is presented in a sequential order as described in section 2 .

Table 2. Regression analysis

Note. $*<0.10, * *<0.05$ and $* * *<0.001$.

The OLS (Ordinary Least Square) regression shows a corresponding probability value of $0.000<0.05$ for the 
Ex-Rate (the independent variable) which is significant to explain the WPI (dependent variable). On the other hand, the weighted regression model which is comparatively computed here to treat all the observation with an equal treatment, shows a p-value of $0.000<0.05$ for the IV which is also significant to explain the WPI being the dependent variable. Both of the regressions exhibit significance of IV (Exchange rate) to explain the DV (WPI) but no reliance is yet based on this end and we further our analysis to check for the existence of any serial correlation within the series (see, Keirs, 1997; Richardson \& Wu, 1971).

Table 3. Test of autocorrelation

\begin{tabular}{|c|c|c|c|c|c|c|}
\hline \multirow[b]{2}{*}{$\operatorname{Lags}(p)$} & \multicolumn{3}{|c|}{ Durbin Watson LM Test } & \multicolumn{3}{|c|}{ Breusch-Godfrey LM Test } \\
\hline & $\mathrm{Chi}^{2}$ & df & Prob $>\mathrm{chi}^{2}$ & $\mathrm{Chi}^{2}$ & $\mathrm{df}$ & Prob $>\mathrm{chi}^{2}$ \\
\hline 10 & 9.768 & 10 & 0.4610 & 9.778 & 10 & 0.4601 \\
\hline
\end{tabular}

Note. $*<0.10, * *<0.05$ and $* * *<0.001$.

Post regression diagnostic tests of Durbin's alternative and Breusch-Godfrey exhibit corresponding probability values of 0.4610 and 0.4601 respectively that are more than $\partial .05$ on the basis of which, we fail to reject the null hypothesis that there is no autocorrelation rather we accept it against the alternative hypothesis. Logically being proved that initial computation of regression is stable in all respect and we continue to test the null that there is no ARCH effect in the model (see, Ali, 1987; Farebrother 1980) for the purpose of which, the LM test for ARCH effect is used to test the aforementioned null hypothesis (see, Table 4).

Table 4. LM test for ARCH

\begin{tabular}{cccc}
\cline { 2 - 4 } & \multicolumn{4}{c}{ LM test for autoregressive conditional heteroskedasticity (ARCH) } \\
\cline { 2 - 4 } & Chi2 $(p)$ & df & Prob $>$ chi2 \\
10 & 23.636 & 10 & $0.0228^{* *}$ \\
\hline
\end{tabular}

Note. $*<0.10, * *<0.05$ and $* * *<0.001$.

The corresponding probability value of Lagrange Multiplier test is $0.028<0.05$ that supports us to reject the null hypothesis in the favor of the alternative that there is an $\operatorname{ARCH}(p)$ disturbance and the mean model has clustering volatility (see, Figure 2).
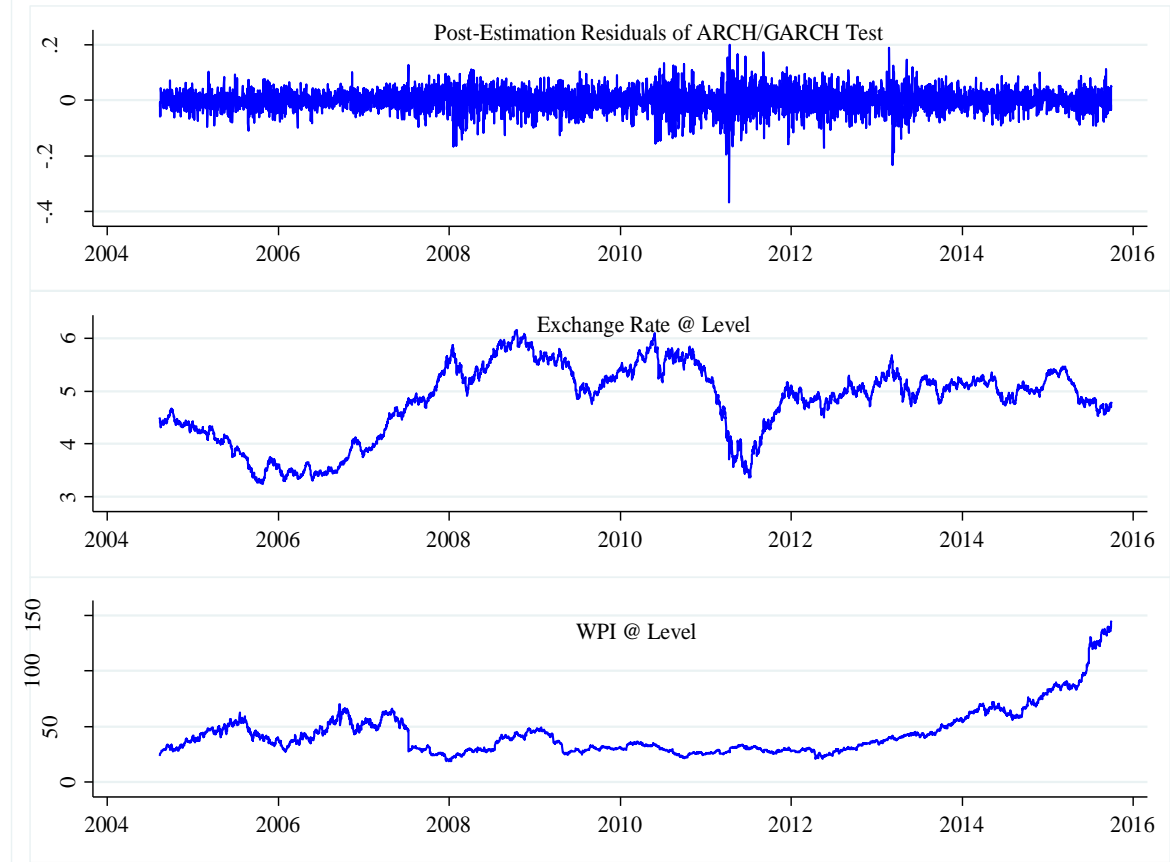

Figure 2. Clustering volatility 
In Figure 2, three variables such as WPI, Exchange rate and the residual of both which is created after the LM (Lagrange Multiplier) test is presented in which the post-estimated residual plot after the LM test for ARCH effect shows a very nice clustering volatility of the residual throughout the period under study. Comparatively, the period from Jan-2008 to Jan-2014 (the maximum period of the residual) shows a consistent tendency of the low clustering volatility that follows the low clustering volatility in the aforementioned series (see, Oh et al., 2006; Lux \& Marchesi, 2000). The graphical presentation of the residual after the LM test also evidences the existence of the clustering volatility in the series but further test of autoregressive conditional heteroskedasticity and its generalized form so called GARCH is to be tested for investigating both the internal and external shock to the dependent variable (Bollerslev, 1986).

Table 5. ARCH family regression

\begin{tabular}{|c|c|c|c|c|c|c|c|}
\hline \multirow{3}{*}{$\begin{array}{l}\text { Sample: } \\
\text { Distribution: } \\
\text { Log likelihood = }\end{array}$} & \multicolumn{4}{|c|}{ Aug. 12, 2004 to Sep. 30, 2015} & \multirow{3}{*}{$\begin{array}{l}\text { Number of obs } \\
\text { Wald } \operatorname{chi}^{2}(.)\end{array}$} & \multirow{2}{*}{$\begin{array}{l}= \\
=\end{array}$} & \multirow{2}{*}{$\begin{array}{r}4,067 \\
1013.11\end{array}$} \\
\hline & Gaussian & & & & & & \\
\hline & -13621.8 & & & & & $=$ & 0.000 \\
\hline D.WPI & & OPG & & & \multirow{2}{*}{\multicolumn{3}{|c|}{ [95\% Conf. Interval] }} \\
\hline & Coef. & Std. Err. & $\mathrm{Z}$ & $\mathrm{P}>|\mathrm{z}|$ & & & \\
\hline WPI & & OPG & & & \multirow{2}{*}{\multicolumn{2}{|c|}{29.49108}} & \\
\hline Constant & 29.53804 & .02396 & 1232.80 & $0.000 * * *$ & & & 29.585 \\
\hline \multicolumn{8}{|l|}{ HET } \\
\hline D.Ex-Rate & -.3604991 & .1446191 & -2.49 & $0.013^{* *}$ & \multicolumn{2}{|c|}{-.6439473} & -.077051 \\
\hline \multicolumn{8}{|l|}{$\mathrm{ARCH}$} \\
\hline \multicolumn{8}{|l|}{$\mathrm{ARCH}$} \\
\hline $\begin{array}{r}\text { L1. } \\
\text { GARCH }\end{array}$ & .9788172 & .0890144 & 11.00 & $0.000^{* * * *}$ & \multicolumn{2}{|c|}{.8043523} & 1.153282 \\
\hline L1. & .0283531 & .0340106 & 0.83 & $0.044 * *$ & \multicolumn{2}{|c|}{-.0383064} & .0950127 \\
\hline
\end{tabular}

Note. $*<0.10, * *<0.05$ and $* * *<0.001$.

$$
\begin{gathered}
y_{t}=29.53804, \sigma_{t}^{2}=0.97788172+-0.3604991 \varepsilon_{t-1}^{2}+0.809 \sigma_{t-1}^{2}, y_{t}=D . W P I_{t}-H E T_{t}-W P I_{t-1} \\
Z=29.53804 / 0.2396=1232.80
\end{gathered}
$$

Table 5 shows the Gaussian normal ARCH and GARCH model in which, the corresponding probability value of $\mathrm{z}$ statistics is 0.000 for D.WPI which is significant to explain the dependent variable. In addition, Ex-Rate is treated as an external shock to WPI which exhibits a $\mathrm{z}$ statistic $=-0.3604991 / 0.1446191=-2.49$ with a $p$-value of 0.013 and that is strongly significant to explain the dependent variable (WPI). Both ARCH and GARCH show strongly significant $p$-values of 0.000 and 0.044 respectively that document the volatility of the Ex-Rate on WPI and we can understand that the previous year's volatility of WPI can influence the future volatility of the WPI as an internal shock and the Ex-Rate previous year's volatility can also influence the WPI as an external shock. Concisely, the findings present clustering volatility of the WPI that its previous period influences its future period while the exchange rate's previous volatility influences the WPI as an external shock in the Chinese Economy.

The existence of serial correlation is a matter of concern that we test the null hypothesis that there is no autocorrelation in the residual against the alternative being there is autocorrelation in the residual (see, Engle, 2001; Bollerslev et al., 2007; Bauwens et al., 2006).

Table 6. Cumulative periodogram white noise

\begin{tabular}{lll}
\hline Bartlett's (B) Statistics & $=$ & 0.8712 \\
\hline Prob $>$ B & $=$ & 0.4362 \\
\hline 5 and $* * *<0.001$. & &
\end{tabular}

The p-value for the Cumulative Periodogram test is 0.4362 which is $>0.05$ and is not significant to statistically support us in rejecting the null hypothesis in favor of the alternative, rather we accept the null hypothesis that the residuals are random and are normally distributed across the sample (see, Dyer \& Keating, 1980). Therefore, we 
can conclude that the randomness and normal distribution of the residuals within the series is a desirable sign of validity and stability of all the models that are applied herein on which we can rationally present the findings and conclude the paper.

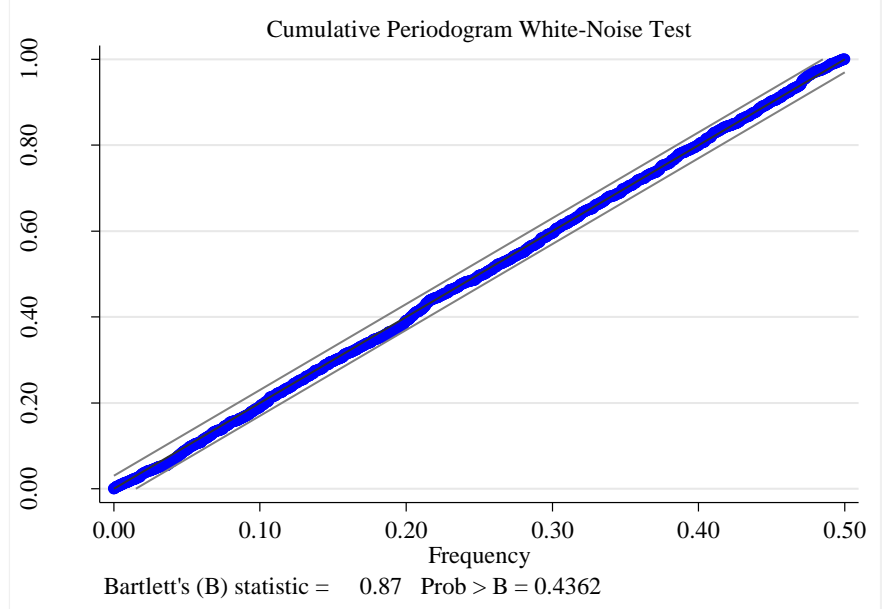

Figure 3. Bartlett's white noise test

Figure 3 represents the same probability of the cumulative periodogram test shown in table 6 to be 0.4362 and documents that the residuals are randomly white noise and within the bands.

\section{Discussion and Conclusion}

Exchange rate has been highly volatile for many developed and developing countries and the central focus has always been on to investigate the effect of foreign exchange rate on other macroeconomic variables (Arize et al., 2000). Since, Chinese economic is highly integrated within the global economy and the use of foreign currencies are transacted in a large scale in almost all its economic and financial dealings, systematically makes the country vulnerable to this phenomenon (see for instance, Maćkowiak, 2007; Kuralbayeva, 2011; Aizenman et al., 2012), we extend our investigation to determine the influences of exchange rate on its WPI for which, a set of time series data that is arranged on daily basis representing 4,067 observation from August 12, 2004 to September 30, 2014 is used in this paper for the stated empirical investigation. The competing null hypothesis (the exchange rate affects the WPI as an external shock) is tested by a set of econometric models in a sequential order i.e. ADF, OLS and Weighted Linear Regression and ARCH and GARCH effect including a series of diagnostic tests to check the stability and validity of the models. Both the OLS and weighted regression analysis reveal significant probability values of 0.000 for the exchange rate (IV) which explains the WPI or the dependent variable. On the other hand, ARCH and GARCH statistical analysis reveal that the previous days clustering volatility of WPI tends to influence the future volatility of the WPI as an internal shock while the exchange rate with a p-value of 0.044 also exhibits significance on WPI which means that the previous days clustering volatility and impulsiveness of the exchange rate influences the future volatility of the WPI as an external shock.

\section{Acknowledgements}

The author acknowledges the constructive and valuable comments of the anonymous referees in relation to this article. It is further to acknowledge the research department of Rana University's comments on the paper template preparation.

\section{References}

Aghion, P., Bacchetta, P., Rancière, R., \& Rogoff, K. (2009). Exchange rate volatility and productivity growth: The role of financial development. Journal of Monetary Economics, 56(4), 494-513.

Aizenman, J., Edwards, S., \& Riera-Crichton, D. (2012). Adjustment patterns to commodity terms of trade shocks: The role of exchange rate and international reserves policies. Journal of International Money and Finance, 31(8), 1990-2016. http://doi.org/10.1016/j.jimonfin.2012.05.003

Ali, M. (1987). Durbin-Watson and generalized Durbin-Watson tests for autocorrelations and randomness. 
Journal of Business \& Economic Statistics, 5(2), 195-203. http://doi.org/10.2307/1391900

Almeida, A., Goodhart, C., \& Payne, R. (1998). The Effects of Macroeconomic News on High Frequency Exchange Rate Behavior. The Journal of Financial and Quantitative Analysis, 33(3), 383-408.

Aristotelous, K. (2001). Exchange-rate volatility, exchange-rate regime, and trade volume: Evidence from the $\begin{array}{lllll}\text { UK-US export function (1889-1999). Economics } & \text { Letters, } & \text { 72(1), } & \text { 87-94. }\end{array}$ http://doi.org/10.1016/S0165-1765(01)00414-1

Arize, A. C., Osang, T., \& Slottje, D. J. (2000). Exchange-Rate Volatility and Foreign Trade: Evidence from Thirteen LDC's. Journal of Business \& Economic Statistics, 18(1), 10-17. http://doi.org/10.2307/1392132

Baldwin, R., \& Krugman, P. (1989). Persistent Trade Effects of Large Exchange Rate Shocks. Quarterly Journal of Economics, 104(4), 635-654. http://doi.org/10.2307/2937860

Bartlett, M. S. (1955). An Introduction to Stochastic Processes with Special Reference to Methods and Applications. Cambridge: Cambridge University Press.

Baum, C. F. (2005). The Language of Choice for Time Series Analysis. Stata Journal, 5, 46-63.

Bauwens, L., Laurent, S., \& Rombouts, J. V. K. (2006). Multivariate GARCH models: A survey. Journal of Applied Econometrics, 21(1), 79-109. http://doi.org/10.1002/jae.842

Bollerslev, T. (1986). Generalized Autoregressive Conditional Heteroskedasticity. Journal of Econometrics, 31(1), 307-327.

Bollerslev, Tim, J. R. R. \& M. W. (2007). Glossary to ARCH (GARCH). Duke University and NBER. http://doi.org/http://dx.doi.org/10.1093/acprof:oso/9780199549498.003.0008

Box, G. E. P., \& Pierce, D. A. (1970). Distribution of Residual Autocorrelations in Autoregressive-Integrated Moving Average Time Series Models. Journal of the American Statistical Association, 65(332), 1509-1526. http://doi.org/10.1080/01621459.1970.10481180

Cao, S., Dong, W., \& Tomlin, B. (2012). The Sensitivity of Producer Prices to Exchange Rates: Insights from Micro Data (No. 2012-20). Ottawa, Ontario.

Coudert, V., \& Couharde, C. (2007). Real equilibrium exchange rate in China is the renminbi undervalued? Journal of Asian Economics, 18(4), 568-594. http://doi.org/10.1016/j.asieco.2007.03.002

De Grauwe, P. (1988). Exchange rate variability and the slowdown in growth of international trade. Staff Papers-International Monetary Fund, 35(1), 63-84.

Devereux, M. B., \& Engel, C. (2002). Exchange rate pass-through, exchange rate volatility, and exchange rate $\begin{array}{llll}\text { disconnect. Journal of Monetary } & \text { Economics, 49(5), }\end{array}$ http://doi.org/10.1016/S0304-3932(02)00130-7

Dicky, D. A., \& Fuller, W. A. (1979). Distribution of Estimates for Autoregressive Time Series with a Unit Root. Journal of American Statistical Association, 74, 427-431.

Dominguez, K. M. E., \& Tesar, L. L. (2006). Exchange rate exposure. Journal of International Economics, 68(1), 188-218. http://doi.org/10.1016/j.jinteco.2005.01.002

Durbin, J. (1970). Testing for serial correlation in least-squares regression when some of the regressors are lagged dependent variables. Econometrica, 38(3), 410-421.

Dyer, D. D., \& Keating, J. P. (1980). On the Determination of Critical Values for Bartlett's Test. Journal of the American Statistical Association, 75(370), 313-319. http://doi.org/10.2307/2287450

Engel, C. (2006). Equivalence Results for Optimal Pass-through, Optimal Indexing to Exhange Rates, and Optimal Choice of Currency for Exporting Pricing. Journal of the European Economic Association, 4(December), 1249-1260.

Engle, R. (2001). GARCH 101: The Use of ARCH/GARCH Models in Applied Econometrics. Journal of Economic Perspectives, 15(4), 157-168. http://doi.org/10.1257/jep.15.4.157

Engle, R. F. (1982). Autoregressive Conditional Heteroscedasticity with Estimates of the Variance of United Kingdom Inflation. Econometrica, 50(4), 987-1007. http://doi.org/10.2307/1912773

Farebrother, R. W. (1980). the Durbin-Watson Test for Serial Correlation When There Is No Intercept in the Regression. Econometrica, 48(6), 1553-1563. http://doi.org/10.2307/1911150

Jiang, J., \& Kim, D. (2013). Exchange rate pass-through to inflation in China. Economic Modelling, 33, 900-912. 
http://doi.org/10.1016/j.econmod.2013.05.021

Kiers, H. A. L. (1997). Weighted least squares fitting using ordinary least squares algorithms. Psychometrika. http://doi.org/10.1007/BF02295279

Kuralbayeva, K. (2011). Inflation persistence and exchange rate regime: Implications for dynamic adjustment to shocks in a small open economy. Journal of Macroeconomics, 33(2), 193-205. http://doi.org/10.1016/j.jmacro.2010.11.006

Lux, T., \& Marchesi, M. (2000). Volatility Clustering in Financial Markets: A Microsimulation of Interacting Agents. International Journal of Theoretical and Applied Finance, 3(4), 675-702.

Maćkowiak, B. (2007). External shocks, U.S. monetary policy and macroeconomic fluctuations in emerging markets. Journal of Monetary Economics, 54(8), 2512-2520. http://doi.org/10.1016/j.jmoneco.2007.06.021

Oh, G., Um, C. J., \& Kim, S. (2006). Long-term Memory and Volatility Clustering in Daily and High-frequency Price Changes. Analysis, (1), 6. http://doi.org/http://dx.doi.org/10.1016/j.physa.2007.08.061

Rahman, S., \& Serletis, A. (2009). The effects of exchange rate uncertainty on exports. Journal of Macroeconomics, 31(3), 500-507. http://doi.org/10.1016/j.jmacro.2008.12.005

Richardson, D. H., \& Wu, D. M. (1971). A note on the comparison of Ordinary and two -stage Least Square estimation. Econometrica, 39(6).

Sahminan, S. (2007). Effects of exchange rate depreciation on commercial bank failures in Indonesia. Journal of Financial Stability, 3(2), 175-193. http://doi.org/10.1016/j.jfs.2007.04.002

Tokarick, S. (2008). Commodity currencies and the real exchange rate. Economics Letters, 101(1), 60-62. http://doi.org/10.1016/j.econlet.2008.04.008

Wang, K. L., \& Barrett, C. B. (2007). Estimating the effects of exchange rate volatility on export volumes. Journal of Agricultural and Resource Economics, 32(February), 225-255.

$\mathrm{Xu}, \mathrm{Z}$. (2003). Purchasing power parity, price indices, and exchange rate forcasts. Journal of International Money and Finance, 22(1), 105-130. http://doi.org/10.1016/S0261-5606(02)00049-9

Zhang, Z. (2001). Real Exchange Rate Misalignment in China: An Empirical Investigation. Journal of Comparative Economics, 29(1), 80-94. http://doi.org/10.1006/jcec.2000.1705

\section{Copyrights}

Copyright for this article is retained by the author(s), with first publication rights granted to the journal.

This is an open-access article distributed under the terms and conditions of the Creative Commons Attribution license (http://creativecommons.org/licenses/by/3.0/). 